\title{
CrystEngComm
}

CrossMark $<$ click for updates

Cite this: DOI: 10.1039/c4ce01211a

Received 12th June 2014,

Accepted 8th October 2014

DOI: $10.1039 / c 4 c e 01211 a$

www.rsc.org/crystengcomm

\section{Molecular structure and polymorphism of a cyclohexanediol: trans-1,4-cyclohexanedimethanol $†$}

\author{
Mário T. S. Rosado, ${ }^{\text {a }}$ Teresa M. R. Maria, ${ }^{\text {*a }}$ Ricardo A. E. Castro, ${ }^{\text {b }}$ João Canotilho, ${ }^{b}$ \\ Manuela Ramos Silva ${ }^{c}$ and M. Ermelinda S. Eusébio ${ }^{a}$
}

\begin{abstract}
This study aims to investigate the molecular structure and polymorphism of trans-1,4-cyclohexanedimethanol, including the bi-axial/bi-equatorial equilibrium and the nature of the intermolecular $\mathrm{H}$-bond networks in condensed phases created by the hydroxyl group torsions. The full conformational space of the single molecule was explored by MP2 calculations, showing that the optimized bi-equatorial conformers have similar stability and the bi-axial ones have much higher energies. The hydroxymethyl substituents have preference for gauche/anti or gauche+/gauche- conformations. Polymorphic forms were generated by crystallization from solutions and by cooling the melt, which were characterized by a combination of techniques: DSC, PLTM and XRD. Two polymorphs were isolated and their crystal structures were solved by direct methods based on single-crystal X-ray analysis. Both were found to contain two of the most stable conformers found in the computational calculations. The influence of $\mathrm{H}$-bonding in the polymorphic structures was verified by analysis of the structural differences between the geometries present in the polymorphs determined by XRD and their single molecule counterparts resulting from the theoretical calculations. The bi-axial conformations are destabilized over the bi-equatorial ones in isolated and crystalline forms of trans-1,4-cyclohexanedimethanol.
\end{abstract}

\section{Introduction}

Dihydroxyl cyclohexane derivatives are a class of compounds that present rich polymorphism. For instance, two of the dihydroxylated derivatives, cis-1,2- and cis-1,4-cyclohexanediols, show cubic plastic crystal mesophases. ${ }^{1-3}$ For the isomer trans-1,2-cyclohexanediol, two polymorphic forms have been identified, one of which is metastable. ${ }^{2}$

The trans-1,4 substitution pattern on a cyclohexyl ring yields either bi-equatorial or bi-axial conformers. The bi-axial $v s$. bi-equatorial conformational equilibrium in cyclohexane derivatives is usually governed by high barriers that prevent interconversion at room temperatures but varied energy differences. Although bi-equatorial conformers are frequently the most

\footnotetext{
${ }^{a}$ CQC, Department of Chemistry, University of Coimbra, Rua Larga,

3004-535 Coimbra, Portugal. E-mail: mtulio@qui.uc.pt, troseiro@ci.uc.pt

${ }^{b}$ CEF, Faculty of Pharmacy, University of Coimbra, P-3000-548 Coimbra, Portugal

${ }^{c}$ CEMDRX, Department of Physics, University of Coimbra,

P-3004-516 Coimbra, Portugal

$\dagger$ Electronic supplementary information (ESI) available: The Cartesian coordinates of optimized geometries of all conformers of trans-1,4-cyclohexanedimethanol are presented in Table S1. CCDC 989757, trans-1,4-cyclohexanedimethanol form I, and 1016822, trans-1,4-cyclohexanedimethanol form II, crystal structures at room temperature contain the supplementary crystallographic data for this paper. For ESI and crystallographic data in CIF or other electronic format see DOI: $10.1039 / \mathrm{c} 4 \mathrm{ce} 01211 \mathrm{a}$
}

stable, the bi-axial conformations can also be relevant in the overall population. ${ }^{4}$ For trans-1,4-cyclohexanediol, three solid forms were identified. This compound has the particularity of presenting bi-equatorial conformers in the crystal lattice of two known polymorphs as well as conformers in which the hydroxyl groups have the bi-axial conformation. ${ }^{4,5}$ Theoretical calculations performed for this isomer also show stabilization of bi-axial structures. ${ }^{6}$

It has been noted that the cis/trans relative population affects the 1,4-cyclohexanedimethanol polymerization reactions. ${ }^{7}$ Additionally, the bi-axial/bi-equatorial equilibrium in cyclohexane ring derivatives also has the potential to influence the geometry in supramolecular association occurring in crystallization processes, as well as in polymerization reactions, as seen recently for silver piperazine-pyrazine coordination polymers. ${ }^{8}$ Thus, the knowledge of the way in which the conformational equilibrium in the trans-1,4-cyclohexanedimethanol molecules determines the crystalline forms is very important.

In this work, an investigation on the molecular structure and polymorphism of 1,4-cyclohexanedimethanol is undertaken. This molecule differs from 1,4-cyclohexanediol only in two methylene groups placed between a cyclohexane carbon atom and the $\mathrm{OH}$ group, which may confer more flexibility to the molecule while moving the hydroxyl group away from the ring. Although the study of just another molecule of the same family is not enough to establish general trends, it can be an 
additional contribution to understand the influence of a larger and more flexible substituent in the bi-equatorial/ bi-axial conformational equilibrium and polymorphism of cyclohexanediols.

Besides the importance that dihydroxyl cyclohexane derivatives may have from a perspective of fundamental research, they also find numerous applications in the chemical and pharmaceutical industries. $^{9-13}$ 1,4-Cyclohexanedimethanol is a highly valued and extensively used reagent as a linker molecule in the polymer industry, ${ }^{14-20}$ and for that reason, investigation on more efficient procedures for its synthesis are still undertaken. ${ }^{21,22}$

\section{Experimental and computational procedures}

Materials

trans-1,4-Cyclohexanedimethanol was acquired from B\&K Technology Group China Co., Ltd. $(x>98 \%)$. Solid samples obtained by melt crystallization and by crystallization from ethyl ether and ethyl acetate solutions, by solvent evaporation at $4{ }^{\circ} \mathrm{C}$, were also analysed.

\section{Differential scanning calorimetry (DSC)}

DSC experiments were performed using a Perkin Elmer Pyris1 calorimeter, with an intracooler cooling unit at $-25{ }^{\circ} \mathrm{C}$ (ethylene glycol-water $(1: 1, \mathrm{v} / \mathrm{v})$ cooling mixture). The samples were hermetically sealed in aluminium pans, and as reference, an

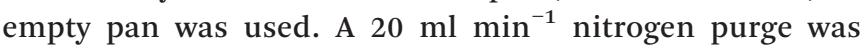
employed. Temperature calibration was performed with highgrade standards, namely, biphenyl (CRM LGC 2610, $T_{\text {fus }}=$ $68.93 \pm 0.03{ }^{\circ} \mathrm{C}$ ) and indium (Perkin Elmer, $x=99.99 \%, T_{\text {fus }}=$ $\left.156.60{ }^{\circ} \mathrm{C}\right) .{ }^{23,24}$ Enthalpy calibration was performed with indium $\left(\Delta_{\text {fus }} H=3286 \pm 13 \mathrm{~J} \mathrm{~mol}^{-1}\right) .{ }^{23}$ DSC curves were analyzed with Pyris software version 3.5.

\section{Polarized light thermal microscopy (PLTM)}

A DSC600 hot stage Linkam system with a Leica DMRB microscope and a Sony CCD-IRIS/RGB video camera was used. The images were obtained by combined use of polarized light and wave compensators, using $200 \times$ magnification. Real Time Video Measurement System software by Linkam was used for image analysis.

\section{Infrared spectroscopy (FTIR)}

Spectra of the solids were recorded at room temperature with the $\mathrm{KBr}$ pellet technique using a ThermoNicolet IR300 FTIR spectrometer at a resolution of $1 \mathrm{~cm}^{-1}$.

\section{Single-crystal X-ray diffraction (XRD)}

Single crystals of polymorph I were collected from the commercial compound, and single crystals of polymorph II were collected from mixtures of forms I and II concomitantly crystallized from ethyl ether and ethyl acetate solutions by solvent evaporation at $4{ }^{\circ} \mathrm{C}$. A Bruker-Nonius Kappa Apex II CCD diffractometer using graphite monochromated Mo K $\alpha$ radiation $(\lambda=0.71073 \AA)$ was employed. Direct methods and conventional Fourier synthesis (SHELXS-97) were used to solve the structures, and the refinement was made by fullmatrix least-squares on $F^{2}$ (SHELXL-97). All non-H atoms were refined anisotropically. The $\mathrm{H}$ atoms with exception of the $\mathrm{OH}$ groups were initially placed at idealized calculated positions and refined with isotropic thermal factors while allowed to ride on the attached parent atoms using SHELXL-97 defaults. Coordinates of $\mathrm{H}$ atoms in $\mathrm{OH}$ groups were freely refined. Crystals of polymorph II were found to be sensitive to X-ray irradiation, with the intensities of the reflection decreasing significantly after 12 hours of exposition.

\section{X-ray powder diffraction (XRPD)}

A glass capillary was filled with the powder obtained by grinding the solids. The samples were mounted on an ENRAF-NONIUS powder diffractometer (equipped with a CPS120 detector by INEL), and data were collected for $5 \mathrm{~h}$ using Debye-Scherrer geometry. $\mathrm{Cu} \mathrm{K}_{1}$ radiation was used $(\lambda=1.540598 \AA$ ). Potassium aluminium sulphate dodecahydrate was chosen as an external calibrant. Samples were heated by a hot nitrogen gas stream (Oxford Cryosystems, series 600) at an approximate rate of $6{ }^{\circ} \mathrm{C} \mathrm{min}^{-1}$.

\section{Computational calculations}

All calculations were performed using GAMESS $^{25}$ version 12 Jan 2009 (R3) running in a Linux cluster of PCs. All geometries were fully optimized at the MP2 level of theory using the aug-cc-pVDZ basis set ${ }^{26,27}$ using the default GAMESS parameters. To ensure the nature of the stationary points as local minima in the potential energy surfaces, these were followed by the calculation of vibrational frequencies. The latter calculations were also used to determine properties like the vibrational zero point energy, enthalpy, entropy and Gibbs energy by the usual thermodynamic relationships, considering the ideal gas, harmonic, rigid rotor, and fundamental state approximations.

\section{The molecular conformational space}

The molecular conformations of trans-1,4-cyclohexanedimethanol are the fundamental features that will ultimately determine the way the individual molecules can associate in different manners present in the supramolecular structures of the different polymorphs.

There are two structural features that can determine fundamental differences in intermolecular association in condensed phases that can lead to polymorphism. One of them is the presence of a pair of methyloxy groups at each side of the molecule. This particular arrangement is highly favorable to the establishment of strong hydrogen bonds to neighboring molecules, either as donors or as acceptors. The formation of these intermolecular interactions is highly dependent on which directions these groups are pointing to. 
Also, methyloxy groups in different conformations will lead to different modes of molecular association in the crystalline grid, hence to polymorphism. The other is the inversion ability of the cyclohexane chair ring, interconverting equatorial and axial conformations. These can also produce different polymorphs upon intermolecular association in the crystal. Despite being associated with greater energy differences, the second structural feature is seldom of greater importance than the first because of the much greater energy barriers involved in the ring inversion when compared to the rotations of the methyloxy group. Close to room temperature, the conformational interconversion reactions should be only related to the second structural feature.

Although the ultimate structure and stability of the crystalline phases depend greatly on intermolecular interactions, one cannot deny the fundamental importance played by the availability of the different conformers in single molecules. As such, the starting point to understand the nature of polymorph formation should include a detailed study of the conformational space of individual molecules.

The twisted boat conformations of cyclohexane derivatives are considerably less stable than the chair conformation. Thus, they can be safely discarded from this study because of their much higher energy. The particular disubstituted twisted boat structures that could be stabilized by an intramolecular interaction between substituents are invalidated in trans-1,4-cyclohexanedimethanol because of the distances imposed by the $\mathrm{CH}_{2} \mathrm{OH}$ substituent.

trans-1,4-Cyclohexanedimethanol molecules have a pair of methyloxy groups attached to a cyclohexane ring (in opposite carbon atom positions $\mathrm{C}^{1}$ and $\mathrm{C}^{4}$ ) in either bi-equatorial or bi-axial conformation. Each methyloxy group contributes with two conformationally relevant torsions, corresponding to the four rotations around the $\mathrm{C}^{1}-\mathrm{CH}_{2}$ or $\mathrm{C}^{4}-\mathrm{CH}_{2}$ and the pair of $\mathrm{H}_{2} \mathrm{C}-\mathrm{OH}$ bonds. Assuming three generally stable local minima for each one of the latter four bond rotations per molecule, with approximate dihedral angle values of $-60^{\circ}$, $+60^{\circ}$ or $180^{\circ}$ (gauche-, gauche+ and anti, respectively), there would be $3^{4} \times 2=162$ possible conformers. Symmetry considerations can be used to identify and avoid the calculation of degenerate geometries. There is 4-fold degeneracy in conformers with $C_{1}$ symmetry and 2-fold degeneracy for $C_{\mathrm{i}}$ and $C_{2}$ conformers, whereas $C_{2 \mathrm{~h}}$ conformers are unique, which yields a total of 48 possible symmetry unique conformers.

All those possible local non-degenerate minima were optimized at the MP2/aug-cc-pVDZ level of theory. The geometries of selected conformers relevant to the discussion are presented in Fig. 1. The energetic and structural parameters characterizing all the conformers found are presented in Table 1 . The conformations are described by a set of labels corresponding to dihedral angles close to $-60^{\circ}(\mathrm{g}-),+60^{\circ}(\mathrm{g}+)$ or $180^{\circ}(\mathrm{a})$, arranged in the following manner: $\left(\mathrm{H}-\mathrm{C}^{1}-\right.$ $\mathrm{C}-\mathrm{O})\left(\mathrm{C}^{1}-\mathrm{C}-\mathrm{O}-\mathrm{H}\right)-\left(\mathrm{H}-\mathrm{C}^{4}-\mathrm{C}-\mathrm{O}\right)\left(\mathrm{C}^{4}-\mathrm{C}-\mathrm{O}-\mathrm{H}\right)$.

The conformational space of trans-1,4-cyclohexanedimethanol does not show any mutual interference of the substituent groups, owing to their separation on opposite positions in the cyclohexane ring. Analysis of Table 1 shows that the order of stability does not always follow the relative population because of entropy differences among conformers, arising also from different symmetry/degeneracy degrees. The second most stable conformer (by less than $0.5 \mathrm{~kJ} \mathrm{~mol}^{-1}$ ) is the most abundant (15.61\%).

The internal rotations of the hydroxymethyl substituents do not significantly affect the stability, since the electronic energy of all bi-equatorial conformers differs in less than $4 \mathrm{~kJ} \mathrm{~mol}^{-1}$. Nevertheless, one can note that the gauche-anti conformation of the substituent is preferred, followed by gauche-gauche and then the anti-anti. The reason for the preference for the gauche conformation of the $\mathrm{H}-\mathrm{C}-\mathrm{C}-\mathrm{O}$ torsions over the anti could be related to the minimization of steric repulsion of the oxygen atoms (attached to $\mathrm{CH}_{2}-\mathrm{C}^{1}$ ) and the axial hydrogens (attached to $\mathrm{C}^{2}$ and $\mathrm{C}^{6}$ ) seen in E16 (aa_aa), but the distances of $2.583 \AA$ measured in this conformer are not small enough to ascertain this. However, the preference for the anti conformation of the $\mathrm{C}-\mathrm{C}-\mathrm{O}-\mathrm{H}$ torsion is surely caused by the minimization of steric repulsion, since it always moves the hydrogen hydroxyl atom away from the cyclohexyl hydrogen atoms.

The trans-1,4-cyclohexanedimethanol conformers observed in the crystalline phases, discussed below, correspond to
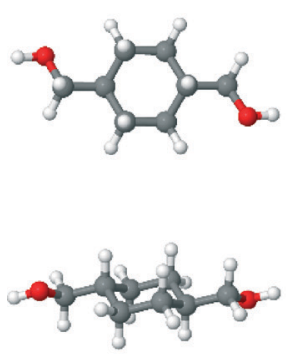

E01
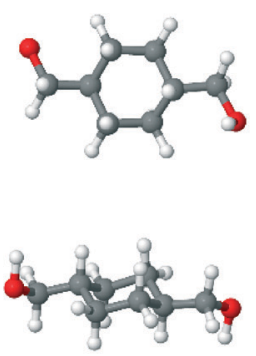

E06
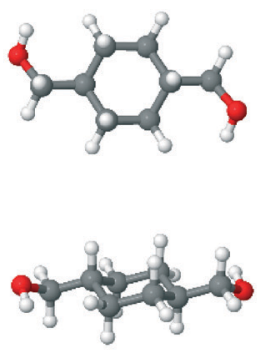

E13
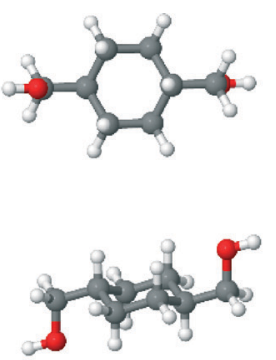

E16
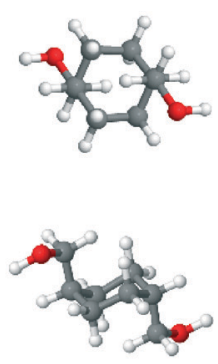

A01

Fig. 1 Several important conformers found for the isolated trans-1,4-cyclohexanedimethanol molecule (top view at the top row and side view at the bottom row). The first three (E01, E06, and E13) were found in crystalline phases; E16 is the anti-anti conformation and A01 is the most stable bi-axial form. 
Table 1 Symmetry, structural and energetic parameters and relative population of the complete conformational space of trans-1,4cyclohexanedimethanol. $g$ : degeneracy, sym: symmetry group, $\Delta E_{0}$ : relative electronic energy, $\Delta E_{0}+E_{\mathrm{ZPE}}$ : relative zero point total energy; $\Delta H$ : relative enthalpy; S: entropy; $\Delta G$ : relative Gibbs energy, and pop: relative population. Bold text refers to conformations found in the crystalline forms

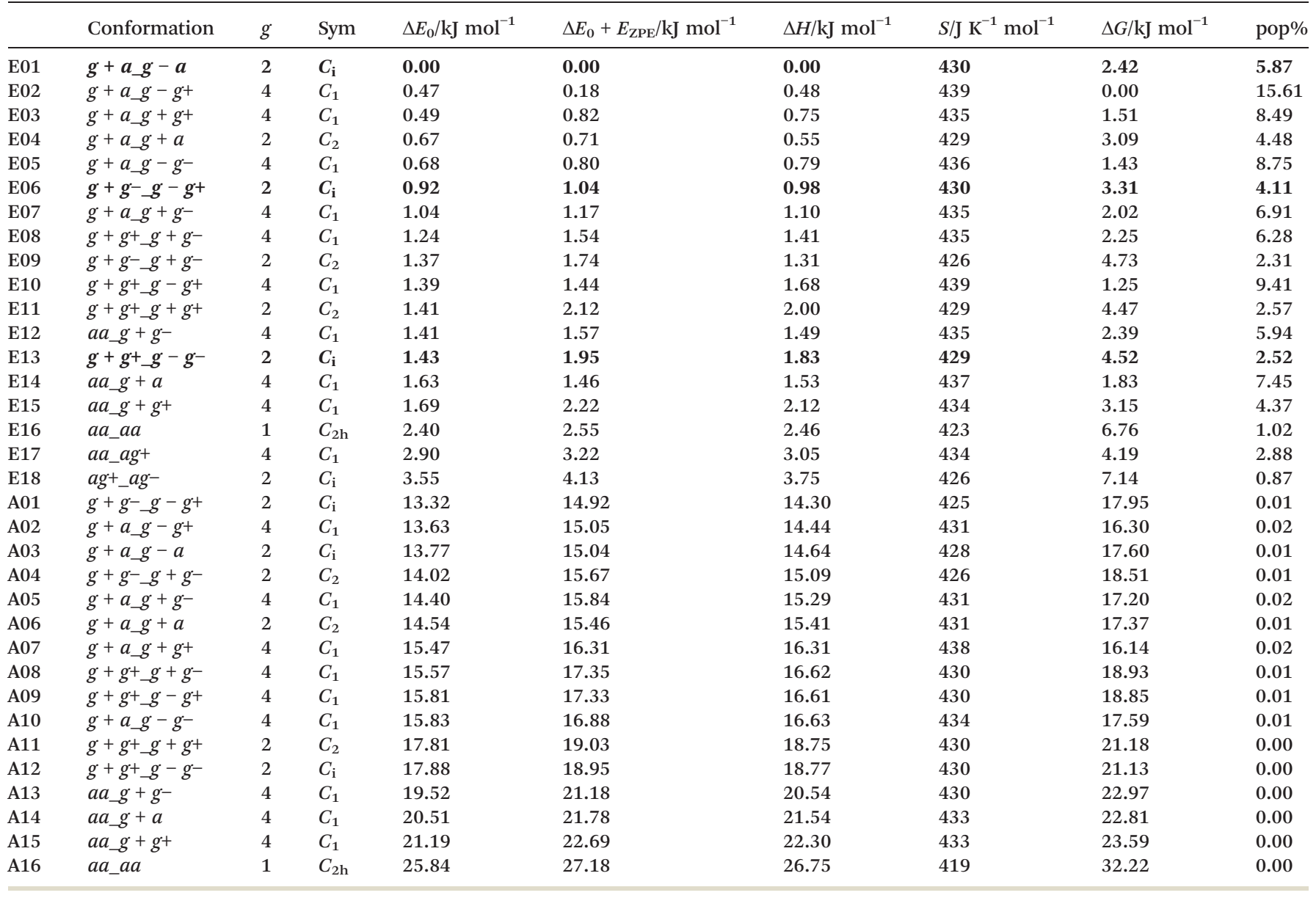

conformers E01 (polymorph I), E06 (polymorphs I and II) and E13 (polymorph II), as shown in Fig. 1. It is worth noting that all these conformers are within $1.5 \mathrm{~kJ} \mathrm{~mol}^{-1}$ of the most stable conformer as predicted in the gas phase; one of them is even the most stable (E01). These observations indicate that the crystalline phase composition of trans-1,4cyclohexanedimethanol depends on the most stable conformers in the gas phase and that no major conformational change is necessary to associate the molecules in the condensed phases. The most discernible distortion in the crystalline phases regards the rotation around the $\mathrm{C}-\mathrm{OH}$ bonds, with dihedral angles $\mathrm{C}-\mathrm{C}-\mathrm{O}-\mathrm{H}$ skewed from their "ideal" gas phase values, particularly in polymorph II $\left( \pm 96.2^{\circ}\right.$ and $\left.\pm 82.3^{\circ}\right)$.

Several of the investigated conformations failed to converge to minima in the potential energy surface. Almost all of the latter were characterized by $\mathrm{H}-\mathrm{C}-\mathrm{C}-\mathrm{O}$ torsions in anti and $\mathrm{C}-\mathrm{C}-\mathrm{O}-\mathrm{H}$ in gauche + or gauche- conformations in one substituent. This particular combination $(a g)$ has the hydroxyl group over the center of the cyclohexane ring and its $\mathrm{H}$ atom very close to the ring axial $\mathrm{H}$ atoms in positions 3 and 5. This repulsion is less considerable in the bi-equatorial forms, and two non-degenerate higher energy conformers were attained.

\section{Structural characterization by single-crystal X-ray diffraction}

Single crystals of two different polymorphs, named I and II, with the appropriate quality to solve their crystal structure, were obtained in the conditions described in the experimental section. Crystallographic data for both polymorphs are presented in Table 2. The ORTEP and packing diagrams for both polymorphs are shown in Fig. 2(a) and (b), respectively.

Polymorph I crystallizes in the centrosymmetric space group $P 2_{1} / c$. The asymmetric unit cell contains two halves of two independent molecules. Both molecules exhibit a chair conformation with the following puckering parameters: puckering amplitude $(Q)=0.565(2) \AA, \theta=180^{\circ}, \phi=0^{\circ}$ and puckering amplitude $(Q)=0.559(2) \AA, \theta=1.52(1)^{\circ}, \phi=0^{\circ}$, for molecules 1 (atoms C1 to C4) and 2 (atoms C5 to C8), respectively. The methanol substituents bond to the six-membered rings in equatorial positions, making an angle of $71.81(10)^{\circ}$ for $\mathrm{C} 4$ and $72.89(10)^{\circ}$ for $\mathrm{C} 8$ with the normal of the Cremer and Pople plane. The molecules' torsion angles are presented in Table 3. The molecules are joined by hydrogen bonds in a 3D network. The structure shows a packing index of 63.6.

Polymorph II crystallizes in a centrosymmetric triclinic unit cell with two independent halves of two molecules in the 
Table 2 Crystal data and structure refinement parameters for trans-1,4cyclohexanedimethanol polymorphs I and II

\begin{tabular}{|c|c|c|}
\hline & Polymorph I & Polymorph II \\
\hline Empirical formula & $\mathrm{C}_{8} \mathrm{H}_{16} \mathrm{O}_{2}$ & $\mathrm{C}_{8} \mathrm{H}_{16} \mathrm{O}_{2}$ \\
\hline Formula weight & 144.21 & 144.21 \\
\hline Temperature (K) & $293(2)$ & $293(2)$ \\
\hline Wavelength $(\AA)$ & 0.71073 & 0.71073 \\
\hline Crystal system & Monoclinic & Triclinic \\
\hline Space group & $P 2_{1} / c$ & $P \overline{1}$ \\
\hline$a(\AA)$ & $10.6792(15)$ & $5.1064(4)$ \\
\hline$b(\AA)$ & $9.1741(14)$ & $5.1749(4)$ \\
\hline$c(\AA)$ & $9.0549(12)$ & $16.3054(10)$ \\
\hline$\alpha\left({ }^{\circ}\right)$ & 90 & $88.250(5)$ \\
\hline$\beta\left({ }^{\circ}\right)$ & $100.211(3)$ & $81.485(5)$ \\
\hline$\gamma\left({ }^{\circ}\right)$ & 90 & $79.662(5)$ \\
\hline Volume $\left(\AA^{3}\right)$ & $873.1(2)$ & $419.20(5)$ \\
\hline$Z$ & 4 & 2 \\
\hline Calculated density $\left(\mathrm{g} \mathrm{cm}^{-3}\right)$ & 1.097 & 1.144 \\
\hline Absorption coefficient $\left(\mathrm{mm}^{-1}\right)$ & 0.077 & 0.080 \\
\hline$F(000)$ & 320 & 160 \\
\hline Crystal size $\left(\mathrm{mm}^{3}\right)$ & $0.17 \times 0.12 \times 0.07$ & $0.6 \times 0.1 \times 0.1$ \\
\hline $\begin{array}{l}\theta \text { range for data } \\
\text { collection }\left(^{\circ}\right)\end{array}$ & $1.9-28.7$ & $3.8-25.8$ \\
\hline Reflections collected/unique & $5023 / 2257$ & $3603 / 1594$ \\
\hline Completeness to $\theta_{\max }$ & $99.7 \%$ (up to $25^{\circ}$ ) & $99.4 \%\left(\right.$ up to $\left.25^{\circ}\right)$ \\
\hline Refinement method & $\begin{array}{l}\text { Full-matrix } \\
\text { least-squares on } F^{2}\end{array}$ & $\begin{array}{l}\text { Full-matrix } \\
\text { least-squares on } F^{2}\end{array}$ \\
\hline Data/restraints/parameters & $2257 / 0 / 97$ & $1594 / 0 / 97$ \\
\hline Goodness-of-fit on $F^{2}$ & 0.989 & 0.917 \\
\hline Final $R$ indices $[I>2 \sigma(I)]$ & $0.0532 / 0.1264$ & $0.0600 / 0.1756$ \\
\hline$R$ indices (all data) & $0.1268 / 0.1577$ & $0.1254 / 0.2336$ \\
\hline $\begin{array}{l}\text { Largest diff. peak and } \\
\text { hole }\left(\mathrm{e} \AA^{-3}\right)\end{array}$ & $-0.168 / 0.189$ & $0.157 /-0.214$ \\
\hline
\end{tabular}

(a)

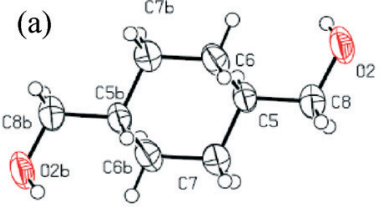

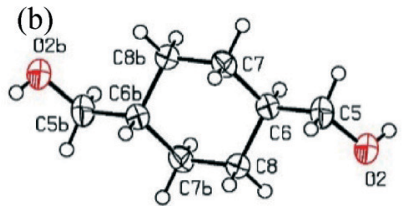

Fig. 2 Molecular structures of trans-1,4-cyclohexanedimethanol polymorphs: (a) form I and (b) form II; ellipsoids were drawn at the $50 \%$ probability level.

asymmetric unit cell. Both molecules display chair conformations with the following puckering parameters: puckering amplitude $(Q)=0.561(2) \AA, \theta=180^{\circ}, \phi=0^{\circ}$ and puckering amplitude $(Q)=0.548(2) \AA, \theta=0^{\circ}, \phi=0^{\circ}$. The C-C-C-C and $\mathrm{C}-\mathrm{C}-\mathrm{C}-\mathrm{O}$ torsion angles are given in Table 3 . The methanol substituents are placed in equatorial positions, making an angle of $70.92(14)^{\circ}$ for $\mathrm{C} 1$ and $70.16(14)^{\circ}$ for $\mathrm{C} 5$, with the normal of the Cremer and Pople plane. The molecules are joined together in layers through H-bonds. This arrangement leads to a more efficient packing, the percentage of filled space being 66.5.
Table 3 Torsion angles $\left(^{\circ}\right)$ of the molecules in polymorphs I and $\mathrm{II}^{a}$

\begin{tabular}{|c|c|c|c|}
\hline \multicolumn{2}{|l|}{ Polymorph I } & \multicolumn{2}{|l|}{ Polymorph II } \\
\hline $\mathrm{C} 3-\mathrm{C} 1-\mathrm{C} 2-\mathrm{C} 3^{i}$ & $55.2(2)$ & $\mathrm{C} 4-\mathrm{C} 2-\mathrm{C} 3-\mathrm{C} 4^{i i i}$ & $54.8(3)$ \\
\hline $\mathrm{C} 4-\mathrm{C} 1-\mathrm{C} 2-\mathrm{C} 3^{i}$ & $-180.0(2)$ & $\mathrm{C} 1-\mathrm{C} 2-\mathrm{C} 3-\mathrm{C} 4^{i i i}$ & $179.5(2)$ \\
\hline $\mathrm{C} 2-\mathrm{C} 1-\mathrm{C} 3-\mathrm{C} 2^{i}$ & $-55.2(2)$ & $\mathrm{C} 3-\mathrm{C} 2-\mathrm{C} 4-\mathrm{C} 3^{i i i}$ & $-54.5(3)$ \\
\hline $\mathrm{C} 4-\mathrm{C} 1-\mathrm{C} 3-\mathrm{C} 2^{i}$ & $-179.0(2)$ & $\mathrm{C} 1-\mathrm{C} 2-\mathrm{C} 4-\mathrm{C} 3^{i i i}$ & $-177.7(2)$ \\
\hline $\mathrm{C} 2-\mathrm{C} 1-\mathrm{C} 4-\mathrm{O} 1$ & $171(2)$ & $\mathrm{O} 1-\mathrm{C} 1-\mathrm{C} 2-\mathrm{C} 3$ & $170.0(2)$ \\
\hline C3-C1-C4-O1 & $-65.9(2)$ & $\mathrm{O} 1-\mathrm{C} 1-\mathrm{C} 2-\mathrm{C} 4$ & $-67.1(3)$ \\
\hline $\mathrm{C} 1-\mathrm{C} 2-\mathrm{C} 3^{i}-\mathrm{C} 1^{i}$ & $-56.4(2)$ & $\mathrm{C} 2-\mathrm{C} 3-\mathrm{C} 4^{i i i}-\mathrm{C} 2^{i i i}$ & $-56.0(3)$ \\
\hline C7-C5-C6-C7 & $-54.9(2)$ & $\mathrm{C} 8-\mathrm{C} 6-\mathrm{C} 7-\mathrm{C}^{i i}$ & $-53.9(3)$ \\
\hline $\mathrm{C} 8-\mathrm{C} 5-\mathrm{C} 6-\mathrm{C7}^{i i}$ & $-180.0(2)$ & $\mathrm{C} 5-\mathrm{C} 6-\mathrm{C} 7-\mathrm{C}^{i i}$ & $-178.3(2)$ \\
\hline $\mathrm{C} 6-\mathrm{C} 5-\mathrm{C} 7-\mathrm{C}^{i i}$ & $54.8(2)$ & $\mathrm{C} 7-\mathrm{C} 6-\mathrm{C} 8-\mathrm{C}^{i i}$ & $53.3(3)$ \\
\hline $\mathrm{C} 8-\mathrm{C} 5-\mathrm{C} 7-\mathrm{C}^{i i}$ & $-179.2(2)$ & $\mathrm{C} 5-\mathrm{C} 6-\mathrm{C} 8-\mathrm{C}^{i i}$ & $176.6(2)$ \\
\hline C6-C5-C8-O2 & $-58.9(2)$ & $\mathrm{O} 2-\mathrm{C} 5-\mathrm{C} 6-\mathrm{C} 7$ & $-176.7(2)$ \\
\hline $\mathrm{C} 7-\mathrm{C} 5-\mathrm{C} 8-\mathrm{O} 2$ & $176.5(2)$ & $\mathrm{O} 2-\mathrm{C} 5-\mathrm{C} 6-\mathrm{C} 8$ & $60.2(3)$ \\
\hline $\mathrm{C} 5-\mathrm{C} 6-\mathrm{C} 7^{i i}-\mathrm{C} 5^{i i}$ & $55.6(2)$ & $\mathrm{C} 6-\mathrm{C} 7-\mathrm{C} 8^{i i}-\mathrm{C}^{i i}$ & $-55.0(3)$ \\
\hline
\end{tabular}

The differences in packing of the molecules in both polymorphs arise from the different conformations of the molecules (Table 3 ) and consequent distinctive $\mathrm{H}$-bonding networks. Hydrogen bond details are given for both polymorphs in Fig. 3 and in Table 4.

In polymorph $\mathrm{I}$, the angle between the line defined by the substituted carbons and the $\mathrm{O}-\mathrm{H}$ line is $31^{\circ}$ and $96^{\circ}$, for
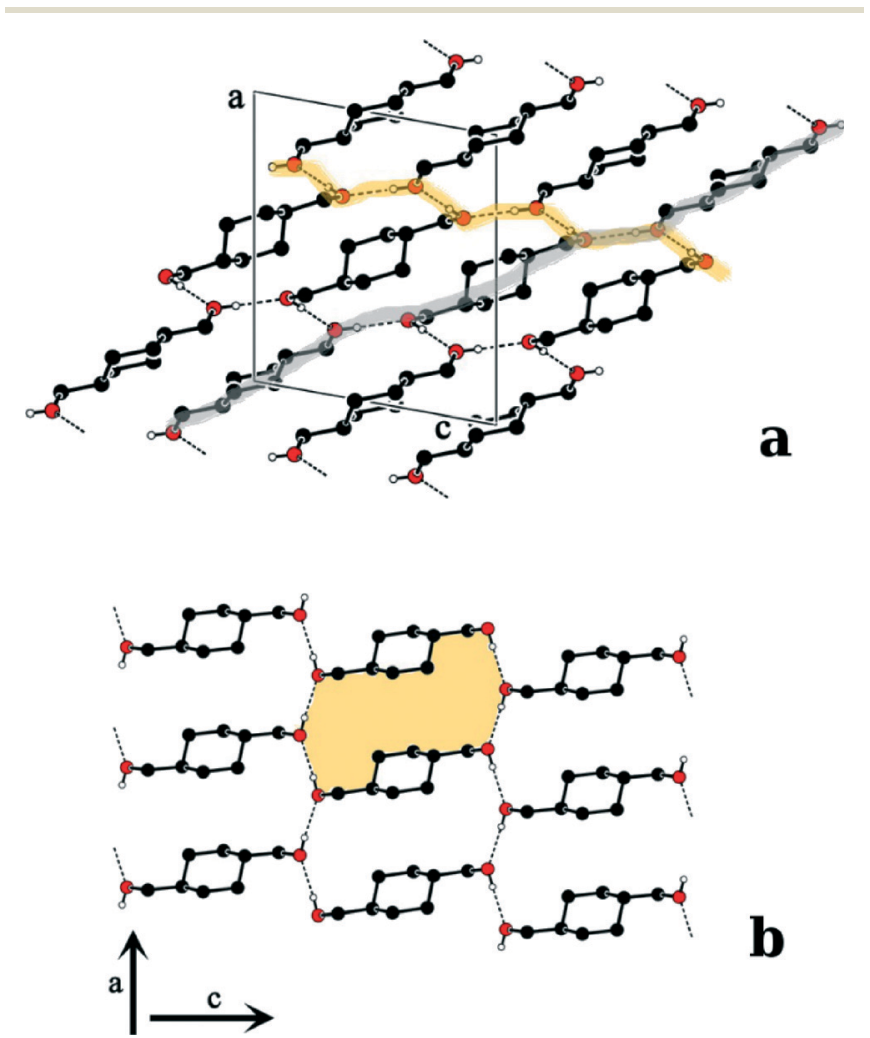

Fig. 3 Hydrogen bond network of trans-1,4-cyclohexanedimethanol: a) projection over the $b$ axis for polymorph I and b) one of the layers for polymorph II. Dashed lines depict hydrogen bond interactions. All hydrogen atoms not involved in $\mathrm{H}$ bonding were omitted for clarity. For polymorph I, the [001] chains are highlighted in yellow and the [102] chains in grey. For polymorph II, one of the rings is highlighted in yellow, see text for details. 
Table 4 Hydrogen bond details for polymorphs I and II of trans-1,4-cyclohexanedimethanol

\begin{tabular}{|c|c|c|c|c|c|c|}
\hline Polymorph & $\mathrm{D}-\mathrm{H} \cdots \mathrm{A}$ & D-H/Å & $\mathrm{H} \cdots \mathrm{A} / \AA$ & $\mathrm{D} \cdots \mathrm{A} / \mathrm{A}$ & $\mathrm{D}-\mathrm{H} \cdots \mathrm{A} /{ }^{\circ}$ & Symmetry code \\
\hline & $\mathrm{O} 2-\mathrm{H} 2 \cdots \mathrm{O} 1^{i v}$ & $0.78(3)$ & $1.98(3)$ & $2.764(2)$ & $174(3)$ & $1 / 2+z$ \\
\hline
\end{tabular}

molecules 1 and 2, respectively. Thus, the molecules are $\mathrm{H}$-bonded in such a way that infinite chains running in the directions [102] and [001] are formed, joining all the molecules in a 3D network. Using graph-set analysis, ${ }^{28}$ the second-level chains (arising from pairwise combinations of two distinct types of hydrogen bonds) have graph-set descriptors $\mathrm{C}_{2}^{2}(4)$ and $\mathrm{C}_{2}^{2}(18)$. When viewed in projection along the $b$ axis, the pattern looks similar to the one found for polymorph II.

In polymorph II, the angle between the line defined by the substituted carbons and the $\mathrm{O}-\mathrm{H}$ line is $50^{\circ}$ and $99^{\circ}$ and the molecules are H-bonded forming rings $\mathrm{R}_{4}^{4}(22)$. The neighboring rings are all part of the same layer as the chains, with graph-set descriptor $\mathrm{C}_{2}^{2}(4)$.

\section{Thermal behaviour}

A typical DSC curve obtained on heating the original compound (polymorph I, as confirmed later by X-ray powder diffraction), performed between 25 and $75{ }^{\circ} \mathrm{C}$, at a scanning

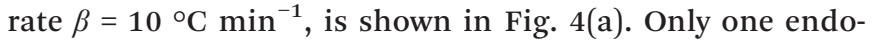
thermic transition is observed, which is assigned to the fusion process, $T_{\text {fus }}=66.05 \pm 0.03{ }^{\circ} \mathrm{C}, \Delta_{\text {fus }} H=17.0 \pm 0.2 \mathrm{~kJ} \mathrm{~mol}^{-1}$, as confirmed by PLTM experiments (Fig. 5(a)). The numerical values presented are the mean of five independent experiments, with the uncertainty expressed as one standard deviation.

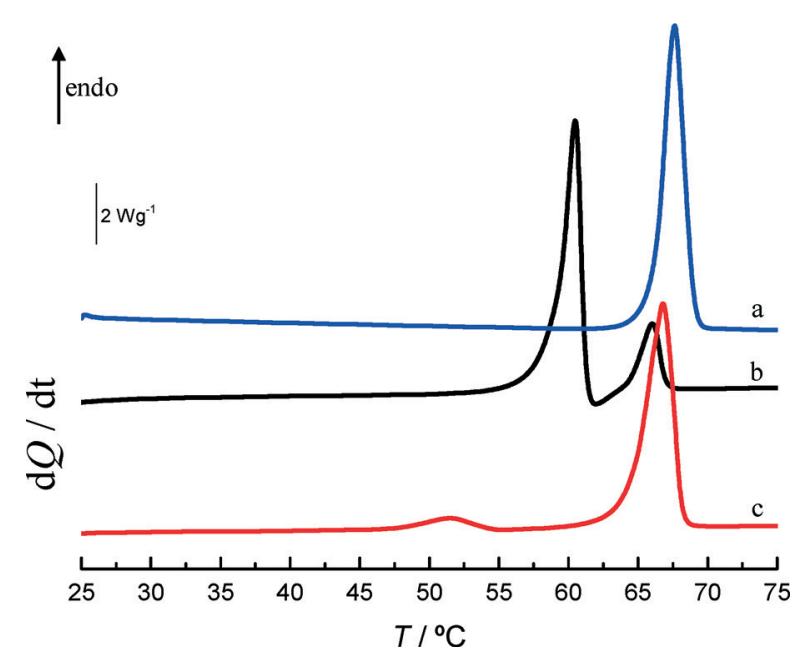

Fig. 4 DSC heating curves of trans-1,4-cyclohexanedimethanol: a) original compound, polymorph I, $m=2.28 \mathrm{mg}$; b) solid obtained from ethyl ether crystallization at $4{ }^{\circ} \mathrm{C}, m=1.33 \mathrm{mg}$; $\mathrm{c}$ ) solid obtained from ethyl acetate crystallization at $4^{\circ} \mathrm{C}, m=2.48 \mathrm{mg} ; \beta=10^{\circ} \mathrm{C} \mathrm{min}^{-1}$. (a)

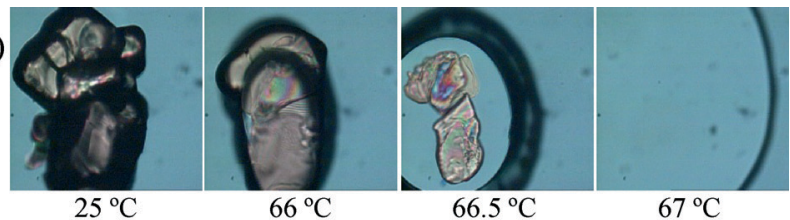

(b)

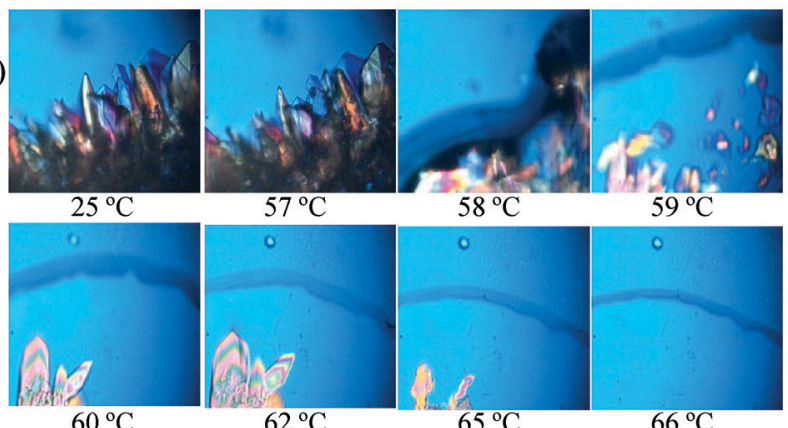

(c)

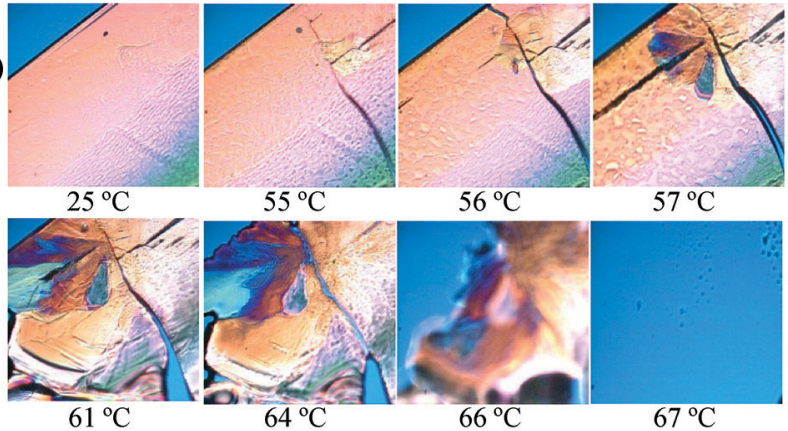

(d)

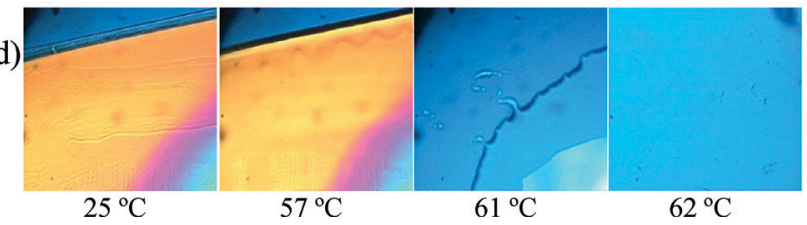

Fig. 5 PLTM images of heating runs of a trans-1,4-cyclohexanedimethanol sample. a) Original compound, polymorph I; b) crystallized from ethyl ether solution at $4{ }^{\circ} \mathrm{C}$; (c and d) crystallized from ethyl acetate solution at $4{ }^{\circ} \mathrm{C} ; \beta=10^{\circ} \mathrm{C} \mathrm{min}^{-1}$; magnification $200 \times$.

trans-1,4-Cyclohexanedimethanol polymorph II was obtained concomitantly with small amounts of polymorph I from samples crystallized both from ethyl ether and ethyl acetate at $4{ }^{\circ} \mathrm{C}$ (the DSC curves obtained in the heating process of two samples crystallized from these solvents, at $4{ }^{\circ} \mathrm{C}$, are shown in Fig. $4(\mathrm{~b})$ and (c), respectively).

In Fig. 4(b), relative to the sample crystallized from ethyl ether, two endothermic transitions are observed, which can be ascribed to fusion of polymorphs II and I. The melting 
temperature of polymorph II is $T_{\text {fus }}=59.4 \pm 0.3{ }^{\circ} \mathrm{C}(n=16)$. Between the two fusion processes, crystallization occurs (liquid $\rightarrow$ I), which is also observed in PLTM experiments (Fig. 5(b)). If form I was already present in this sample, it would be expectable to seed conversion from form II (as in Fig. 4c). Having seen the form II melting (Fig. 4b) suggests that only a negligible amount of form $\mathrm{I}$ is present.

For trans-1,4-cyclohexanedimethanol crystallized from ethyl acetate (Fig. 4(c)), two endothermic transitions are also visualized: the less energetic one, between 45 and $55{ }^{\circ} \mathrm{C}$, corresponds to a solid-solid transition (II $\rightarrow$ I) and the other one to the fusion of form I just produced, as can also be seen by PLTM (Fig. 5(c)). It is of note that it was possible to collect pure form II from samples crystallized from ethyl acetate and perform analysis by PLTM and infrared spectroscopy (Fig. 5(d) and 6(c1), respectively). In Fig. 6(c2), the infrared spectrum of another trans-1,4-cyclohexanedimethanol sample, collected from the crystallization from ethyl acetate solution, is also shown, where the presence of polymorph I is clearly evidenced. This is also observed in the infrared spectrum of a sample crystallized from ethyl ether (Fig. 6(b)). A few differences in the spectra could be ascribed to each polymorph. The peaks at 3250 and $720 \mathrm{~cm}^{-1}$ were assigned to polymorph I, while the other form has distinct peaks near 3400, 1380 and $600 \mathrm{~cm}^{-1}$. The lower frequency of the $v(\mathrm{OH})$ bands of polymorph I at around $3300-3250 \mathrm{~cm}^{-1}$ is consistent with its stronger intermolecular $\mathrm{H}$ bonds than in polymorph II (see Table 4).

\section{Polymorphs generated by melt cooling}

Cooling molten trans-1,4-cyclohexanedimethanol was carried out by DSC and PLTM at several scanning rates between 2 and $10{ }^{\circ} \mathrm{C} \mathrm{min}^{-1}$. Complex DSC crystallization curves were often obtained, as illustrated in Fig. 7.A, curves (a) and (b), typically for molten compound obtained from powder samples (the commercial sample). A simpler crystallization profile was often obtained if the starting material was a crystal of bigger size (e.g. crystals obtained from ethyl acetate Fig. 7.A, curves (c) to (e)). A complex DSC crystallization profile
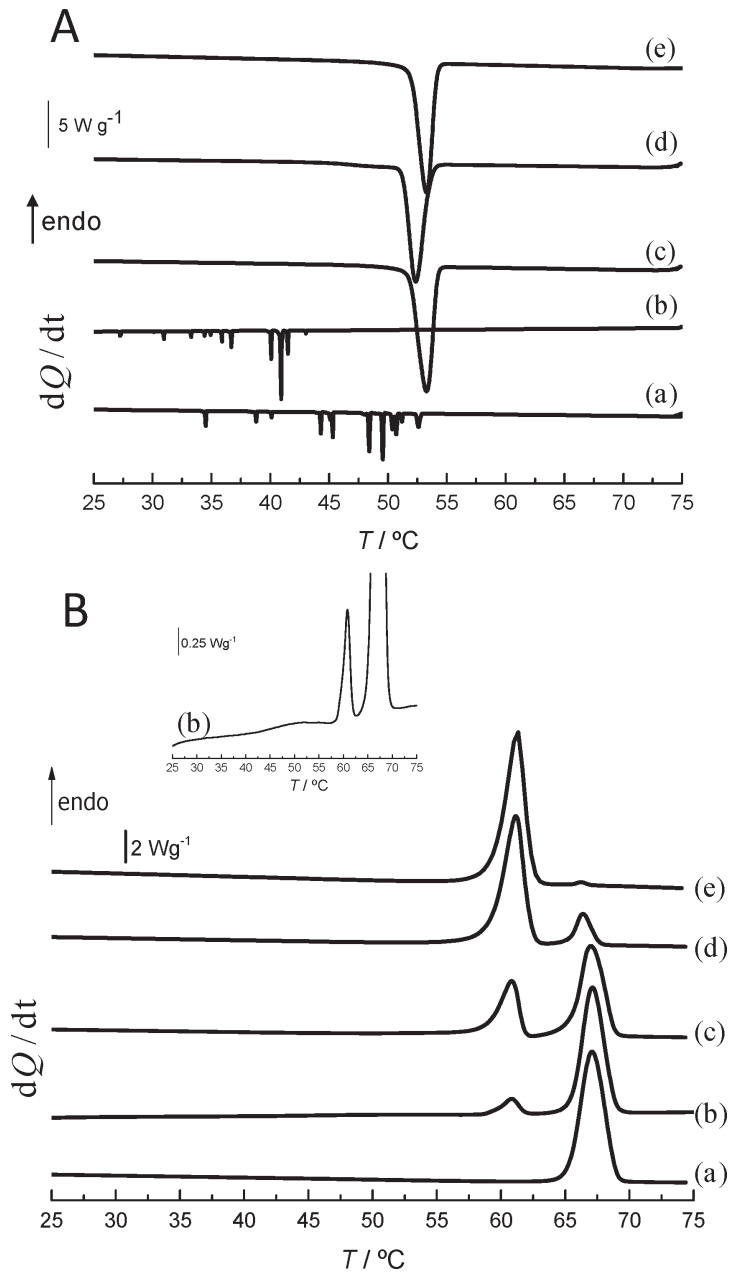

Fig. 7 A. Normalized DSC traces of melt cooling runs of several samples of trans-1,4-cyclohexanedimethanol: ( $\mathrm{a}$ and b) $\beta=-2{ }^{\circ} \mathrm{C} \mathrm{min}^{-1}$; ( $\mathrm{c}$ to e) $\beta=-5^{\circ} \mathrm{C} \mathrm{min}{ }^{-1}$; (a) commercial compound; $m=2.26 \mathrm{mg}$; (b) commercial compound; $m=1.79 \mathrm{mg}$; (c) ethyl acetate; $m=1.96 \mathrm{mg}$; (d) ethyl acetate; $m=1.96 \mathrm{mg}$; (e) ethyl acetate $m=1.25 \mathrm{mg}$. B. Normalized DSC traces of heating runs $\left(\beta=10^{\circ} \mathrm{C} \mathrm{min}^{-1}\right)$ following the corresponding cooling runs in $\mathrm{A}$.

may result from separate liquid drops that, due to kinetic effects, do not crystallize simultaneously, and/or to crystallization of

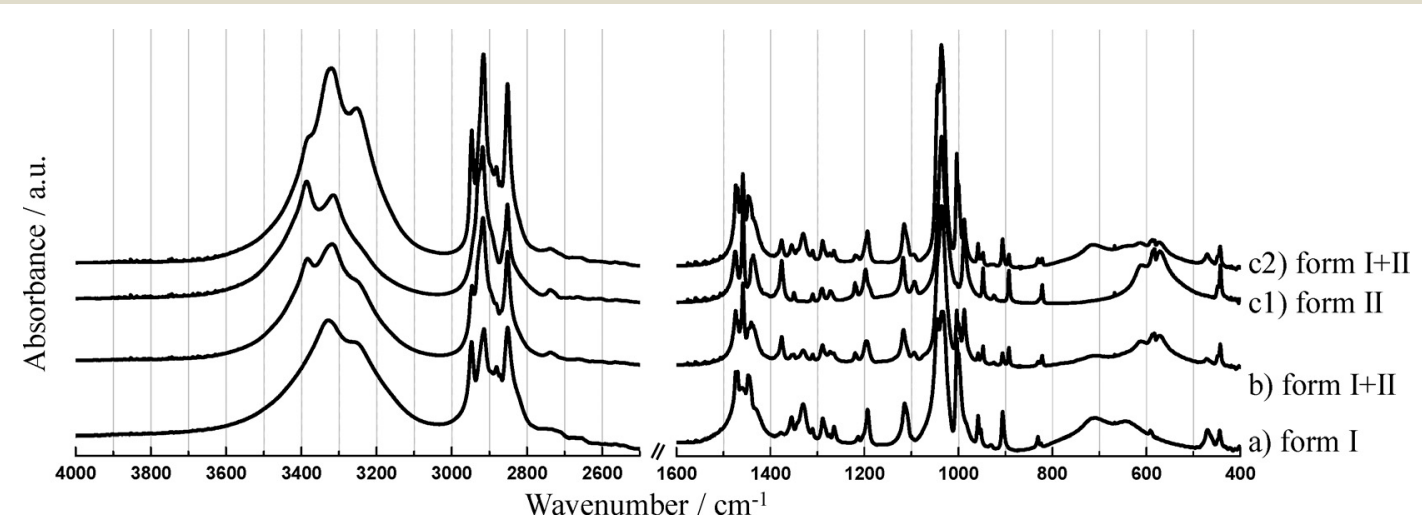

Fig. 6 Infrared spectra of a trans-1,4-cyclohexanedimethanol sample. (a) Commercial compound, polymorph I; (b) crystallized from ethyl ether solution at $4{ }^{\circ} \mathrm{C}$; (c1 and c2) crystallized from ethyl acetate at $4{ }^{\circ} \mathrm{C}$. 
different solid forms, that may be followed by solid-solid interconversion. In order to obtain further insight into these crystallization processes, different melt cooling experiments at $\beta=-2{ }^{\circ} \mathrm{C} \min ^{-1}$ and at $\beta=-10{ }^{\circ} \mathrm{C} \min ^{-1}$ were carried out with different lower temperature limits, as shown in Fig. 8. The subsequent heating runs, carried out immediately after cooling, in the same run, are also shown. In these traces, the fusion of polymorph $\mathrm{I}$ is observed and the enthalpy

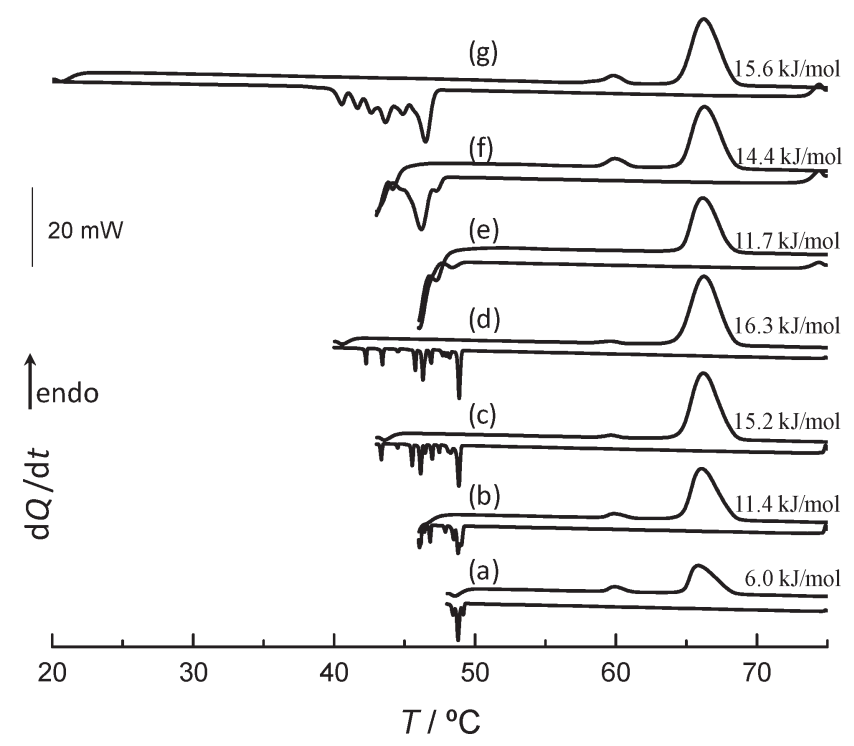

Fig. 8 DSC cooling and heating curves of trans-1,4cyclohexanedimethanol, obtained in different thermal cycles. (a-d) Cooling runs at $\beta=-2{ }^{\circ} \mathrm{C} \mathrm{min}^{-1}$; (e-g) cooling runs at $\beta=-10{ }^{\circ} \mathrm{C} \mathrm{min}^{-1}$. Heating curves at $\beta=10^{\circ} \mathrm{C} \mathrm{min}$. The enthalpy of the main fusion peak is indicated. of fusion increases as the temperature limit reached in the preceding cooling run is lowered. These results are consistent with incomplete liquid crystallization. No evidence of other forms, except small amounts of polymorph II $\left(T_{\text {fus }}=59{ }^{\circ} \mathrm{C}\right)$, was detected in these experiments. When cooling until $25{ }^{\circ} \mathrm{C}$, crystallization occurs between about $55{ }^{\circ} \mathrm{C}$ and $20{ }^{\circ} \mathrm{C}$ with $\Delta_{\text {cry }} H=-15.8 \pm 0.2 \mathrm{~kJ} \mathrm{~mol}^{-1}$. In all the experiments performed by PLTM, crystallization occurs at about $T=48{ }^{\circ} \mathrm{C}$, and immediately a solid-solid transition takes place (starting at $\sim 47^{\circ} \mathrm{C}$; Fig. 9(a)).

DSC traces, representing typical heating run behavior, are shown in Fig. 7.B. These were recorded in heating scans immediately following the cooling runs. From the thermograms obtained, it is obvious that crystallization of molten trans-1,4-cyclohexanedimethanol often gives rise to mixtures of polymorphs I and II in variable compositions (Fig. 7.B(a)-(e) and 9(b) and (c)). A solid-solid transition is also regularly observed at temperatures between 40 and $55^{\circ} \mathrm{C}$ as seen in Fig. 7.B(b) and $9(\mathrm{c})$.

These conclusions are confirmed by X-ray heating/cooling experiments. The simulated powder diffractrograms of polymorphs I and II, together with an experimental diffractogram of the commercial compound, are presented in Fig. 10(a) to (c). Distinguishable peaks ascribed to form I can be found at $2 \theta=12.8,13.8,20.4$ and $27.0^{\circ}$ and to form II at $2 \theta=11.0,18.3,26.4$ and $28.0^{\circ}$. Diffractogram (d) (Fig. 10) was registered in melt cooling and it is consistent with a mixture of forms I and II. Upon heating at $62{ }^{\circ} \mathrm{C}$ (diffractogram (e), Fig. 10), only form I is present. In this figure, the diffractograms of solid samples crystallized in ethyl ether (f) and in ethyl acetate (g) are also included, confirming the predominance of polymorph II.

(a)

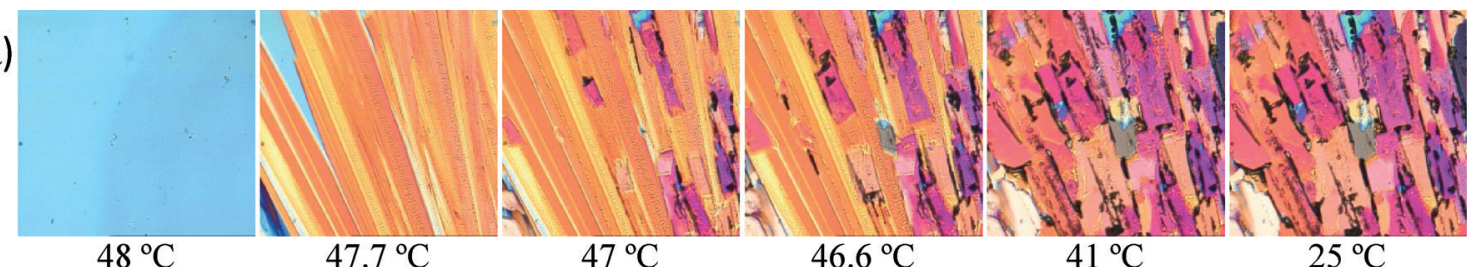

(b)

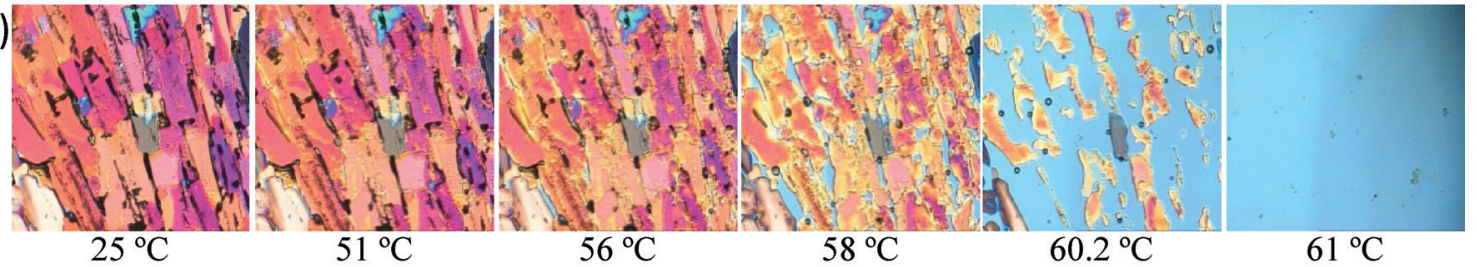

(c)

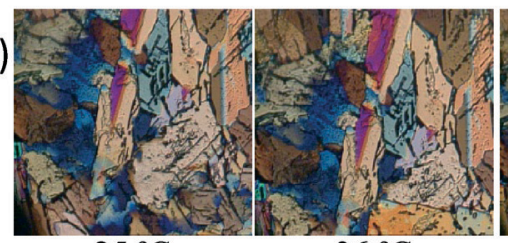

$25^{\circ} \mathrm{C}$

$36^{\circ} \mathrm{C}$

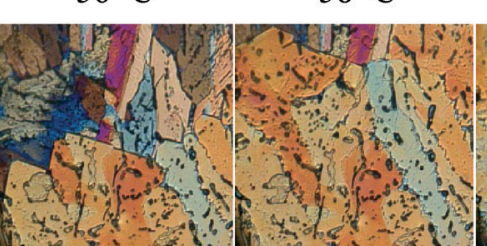

$60.2^{\circ} \mathrm{C}$

$61^{\circ} \mathrm{C}$

Fig. 9 PLTM images of cooling/heating runs of a trans-1,4-cyclohexanedimethanol sample. (a) Melt cooling, $\beta=-5^{\circ} \mathrm{C}$ min $^{-1}$; (b) heating scan of the solid obtained in run a) (form II); (c) heating run of the solid obtained by melt cooling (form I + II). Magnification $200 \times ; \beta=10{ }^{\circ} \mathrm{C}$ min ${ }^{-1}$. 


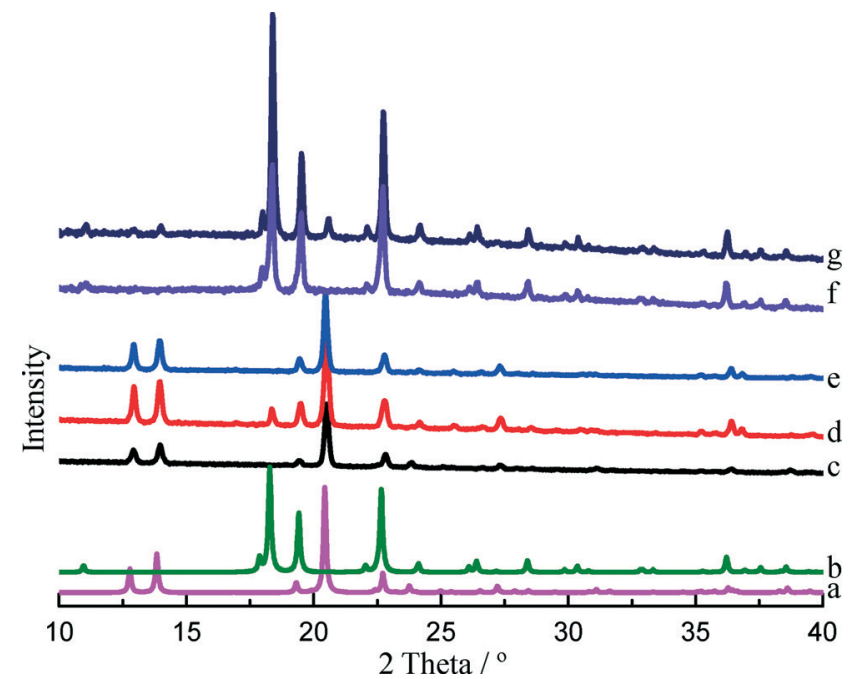

Fig. 10 XRPD of trans-1,4-cyclohexanedimethanol: ( $a$ and b) simulated diffractograms of polymorphs I and II, respectively; (c) commercial sample; (d) obtained in a melt cooling experiment at $40^{\circ} \mathrm{C}$; (e) registered in the heating run following $\mathrm{d}$ at $62^{\circ} \mathrm{C}$; (f) sample crystallized from ethyl ether at $4{ }^{\circ} \mathrm{C} ;(\mathrm{g})$ sample crystallized from ethyl acetate at $4{ }^{\circ} \mathrm{C}$.

\section{Conclusions}

Two polymorphs of trans-1,4-cyclohexanedimethanol were identified for the first time and their crystal structures were resolved by single-crystal X-ray diffraction.

The computational calculations at the MP2/aug-cc-pVDZ level for the isolated molecules show that all equatorial forms are more stable than the axial conformations by about $10 \mathrm{~kJ} \mathrm{~mol}^{-1}$, reflected by the absence of bi-axial molecules in the crystalline forms. The three molecular conformations found in the two polymorphs correspond to some of the lowest energy isolated conformations.

The two polymorphs were characterized by DSC, IR spectroscopy and PLTM. Polymorph I melts at $66.0^{\circ} \mathrm{C}$ with an enthalpy of fusion of $17.0 \mathrm{~kJ} \mathrm{~mol}^{-1}$, whereas for polymorph II, $T_{\text {fus }}=59.4^{\circ} \mathrm{C}$. A solid-solid transition from polymorph II to I was observed from 40 to $55^{\circ} \mathrm{C}$. The appearance of this endothermic transition and the greater density of polymorph II seem to indicate an enantiotropic relationship, ${ }^{29,30}$ where form II would be more stable at temperatures below and form I at temperatures above the transition.

Both polymorphs contain exclusively bi-equatorial conformations, which are also much more stable in the isolated molecules as predicted by the $a b$ initio calculations. These observations emphasize the conclusion that a larger substituent in the cyclohexane ring, with the hydroxyl group further away, favors the bi-equatorial forms to the detriment of the bi-axial ones.

\section{Acknowledgements}

The Coimbra Chemistry Centre is supported by the Fundação para a Ciência e a Tecnologia (FCT), Portuguese Agency for Scientific Research, through the project PEst-OE/QUI/UI0313/2014.
The authors acknowledge the financial support by the project QREN-COMPETE-FCT-PTDC/QUI/QUI/112913/2009.

\section{Notes and references}

1 T. M. R. Maria, F. S. Costa, M. L. P. Leitão and J. S. Redinha, Thermochim. Acta, 1995, 269, 405.

2 M. L. P. Leitão, R. A. E. Castro, F. S. Costa and J. S. Redinha, Thermochim. Acta, 2001, 378, 117.

3 S. V. S. Bebiano, M. T. S. Rosado, R. A. E. Castro, M. Ramos Silva, J. C. Canotilho, T. M. R. Maria and M. E. S. Eusébio, J. Mol. Struct., 2014, 1078, 10.

4 T. M. R. Maria, R. A. E. Castro, S. S. Bebiano, M. R. Silva, A. M. Beja, J. Canotilho and M. E. S. Eusebio, Cryst. Growth Des., 2010, 10, 1194.

5 T. Steiner and W. Saenger, J. Chem. Soc., Perkin Trans. 2, 1998, (2), 371.

6 S. V. S. Bebiano, Isómeros de ciclo-hexanodiol: conformação molecular e polimorfismo. MSc thesis, Coimbra, 2011.

7 M. S. Sulatha, S. Purushotham and U. Natarajan, Polymer, 2002, 43, 6295.

8 S.-C. Hsu, J.-Y. Wu, C.-F. Lee, C.-C. Lee, L.-L. Lai and K.-L. Lu, CrystEngComm, 2010, 12, 3388.

9 W. Silny, P. Chomczynski, M. Czarnecka-Operacz, A. Danczac-Pazdrowka and P. Silny, Postepy. Dermatol. Alergol., 2005, 22, 271.

10 G. Giavaresi, M. Tschon, J. H. Daly, J. J. Liggat, M. Fini, P. Torricelli and R. Giardino, Int. J. Artif. Organs, 2004, 27, 796.

11 E. Barriau, P. A. G. Cormack, J. H. Daly, J. J. Liggat and A. Quincy, Eur. Cells Mater., 2002, 4, 100.

12 A. M. Galal, W. Gul, D. Slade, S. A. Ross, S. Feng, M. G. Hollingshead, M. C. Alley, G. Kaur and M. A. ElSohly, Bioorg. Med. Chem., 2009, 17, 741.

13 N. Li, W. Jia, Y. Zhang, F. Tan and J. Zhang, Int. J. Pharm., 2011, 415, 169.

14 I. K. Jung, K. H. Lee, I. Chin, J. S. Yoon and M. N. Kim, J. Appl. Polym. Sci., 1999, 72, 553.

15 S. R. Turner, J. Polym. Sci., Part A: Polym. Chem., 2004, $42,5847$.

16 Y. Tsai, C.-H. Fan, C.-Y. Hung and F.-J. Tsai, J. Appl. Polym. Sci., 2007, 104, 279.

17 Y. Tsai, C.-H. Fan, C.-Y. Hung and F.-J. Tsai, J. Appl. Polym. Sci., 2008, 109, 2598.

18 D. Cao, Z. Fu and C. Li, J. Appl. Polym. Sci., 2011, 122, 1698.

19 K. K. Baikerikar, M. L. Tulchinsky and J. Argyropoulos, J. Coat. Technol. Res., 2010, 7, 175.

20 Y. Tsai, L.-C. Jheng and C.-Y. Hung, Polym. Degrad. Stab., 2010, 95, 72.

21 A. B. Hungria, R. Raja, R. D. Adams, B. Captain, J. M. Thomas, P. A. Midgley, V. Golovko and B. F. G. Johnson, Angew. Chem., Int. Ed., 2006, 45, 4782.

22 G. Lewandowski, A. Wroblewska and E. Milchert, Polimery, 2007, 52, 39.

23 R. Sabbah, X. W. An, J. S. Chickos, M. L. P. Leitão, M. V. Roux and L. A. Torres, Thermochim. Acta, 1999, 331, 93. 
24 G. Della Gatta, M. J. Richardson, S. M. Sarge and S. Stolen, Pure Appl. Chem., 2006, 78, 1455.

25 M. W. Schmidt, K. K. Baldridge, J. A. Boatz, S. T. Elbert, M. S. Gordon, J. H. Jensen, S. Koseki, N. Matsunaga, K. A. Nguyen, S. J. Su, T. L. Windus, M. Dupuis and J. A. Montgomery, J. Comput. Chem., 1993, 14, 1347.
26 T. H. Dunning, J. Chem. Phys., 1989, 90, 1007.

27 D. E. Woon and T. H. Dunning, J. Chem. Phys., 1993, 98, 1358.

28 M. C. Etter, J. C. Macdonald and J. Bernstein, Acta Crystallogr., Sect. B: Struct. Sci., 1990, 46, 256.

29 A. Burger and R. Ramberger, Microchim. Acta, 1979, 2, 259.

30 A. Burger and R. Ramberger, Microchim. Acta, 1979, 2, 273. 